$\operatorname{VarjaCvetko}$

\title{
SLOVANSKO-ST. INDIJSKA IZOGLOSA ZA POJEM "CAS«
}

F. Bezlaj v rokopisu svoje kritike Skokovega etimološkega slovarja sbh. jezika, ki bo izšla predvidoma $v$ Etimologiji VII, Moskva, navaja sbh. dial. čèlo wdan, dvanajst uru, dan i noć su dva čela (Risanj, Boka Kotorska) in v Črni gori kolje "Zeit, freie Zeit, Musse", dòkolica "Musse", kar po njegovem mnenju snekoliko dvomljivo izvajajo iz pronominalne osnove kolě, koli "quantumu (Berneker, I 674; Barić, Prilozi XV 287; Popović, Gesch. 540), ne da bi vzel kdo $v$ pretres tudi čelok in uje mogoče misliti na slovanski arhaizem iz ide. "qwel- »örtlich und zeitlich fernu.

$\mathrm{Ob}$ tem se ponuja lepa primerjava s sti. $k a \bar{l} l a ́-m$. „čas, določen čas, smrt, usodau. Mayrhofer, Kurzgefasstes etymologisches Wörterbuch des Altinđischen I 202 sl., sti. $k \bar{a} l a \hat{-}$ - jzvaja iz ievr. * $q^{w} e l$ - nobračati se« in primerja isti pomenski prehod pri stcsl. vrěme »čas» $\mathrm{k}$ ievr. *wert- sobračati, vrteti sew. Če $v$ tej povezavi pri * $q^{w} e l$ - izhajamo iz pomena sobračati se«, je bil prvotni pomen verjetno "(določen) čas", čemur ustreza pomen sti. kālá-, deloma sbh. kolje in morda sbh. čèlo, če bi imelo osnovni pomen "določen čas» (prim. dalje alb. ditë »danu $\mathrm{k}$ ievr. *dī-t- "Zeitabschnitt»).

Fonetično je sti. $k \bar{a} l a ́-$ razložljivo < ievr. " $q^{w}$ olo- (sti. $-\bar{a}-<{ }^{*}-0-$ v odprtem zlogu kakor sti. jānu »koleno« : gr. góny; sti. däru »les« : gr. dóry idr.; prim. Brugmann, Grdr.2 I 139. Drugače Thumb-Hauschild, Handbuch des Sanskrit ${ }^{3}$, 1220 sl.). Tudi sbh. kolje in dòkolica je verjetno z znanima sufiksoma -je in -ica razširjeno iz debla * $q^{w} o l o-$ in tako prvotno identično $s$ sti. kālá-, medtem ko mora biti sbh. čèlo staro deblo na -es- $<{ }^{*} q^{w} e l e s-$ (prim. za d. -es- Brugmann, Grdr. ${ }^{2}$ II 1524 in za vokalizem d. -o- ibid. 148 ss.).

Slovansko-st. indijska izoglosa je zlasti zanimiva, ker so za pojem »čası posamezni ievr. jeziki večinoma razvili posebne izraze:

stcsl. časъ »čas, ura«, s. prus. kīsman »Zeit, Weile», alb. kohë »čas, vre mer < ievr. * $q \bar{e}-s k$ '- (Čop, Linguistica IX./2, Ljubljana 1969, 188 ss.).

lat. tempus "Zeitspanne" < ievr. *tempos- "Spanne« $\mathrm{k} *$ temp- wraztezati, vleči, napenjati», kar je razširjeno < *ten- sisto» (Pokorny, IEW 1064).

sti. tan- »Ausbreitung, Fortdauer, Fortpflanzug, Nachkommenschaft«, s. ir. tan sčas" < ${ }^{*} t n \bar{a}$ »Fortdauer, zeitliche Ausdehnung $* \mathrm{k}$ ievr. ${ }^{*} t e n$ - "raztezati, vleči, napenjati« (Pokorny, IEW 1065 sl.).

got. peins (< $\left.{ }^{*} t e ́ n k o s\right)$, pl. peihsa n. "čas« < ${ }^{*} t e n-k$ - »vieči, raztezati, Zeitspanner (Pokorny, IEW 1067). 
got aiws m. udoba, večnostu, stvn. ëwa f., lat. aevus m., aevum n. vživljenjska doba, večnost», aetas f. < aevitas wdoba», alb. eshë »doba, razdobje < < *aiwesjā, gr. âiōn m. "Leben(szeit), Zeit(dauer), lange Zeit, Ewigkeit《 < *aiwōn (Frisk, GEW I 49), vse k ievr. "aju-, *aiw- "živijenjska moču (Pokorny, IEW 17).

nem. Zeit, stvn. «ît, ags. $t \bar{\imath} d$ »čas, ura», arm. $t i$, gen. tioy «starost, leta,

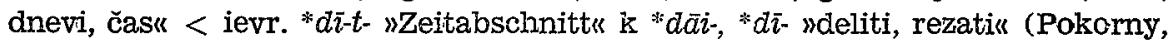
IEW 176). Po Kluge-Mitzka, Etymologisches Wh. der deutschen Sprache 18 880, je s stvn. zït izvengermansko najbliže sorodno alb. ditë wdanu. Na germ. *tī- gre tudi s. angl. tīma »čas, obdobje, življenjska dobar, angl. time (Klein, A Comprehensive Etymological Dictionary of the English Language II 1618).

Nejasno je gr. khrónos m. "(bestimmte) Zeitdauer, Zeitverlauf, Zeit, Lebenszeit, Zeitgrenze» (Frisk, GEW II 1122) in prav tako gr. kairós m. nodločilni, primerni trenutek, letni čas, čas« (Frisk, GEW I 755).

St. indijsko-slovansko izogloso sti. kälá-, sbh. dial. kolje, dòkolica, čèlo lahko uvrstimo med redke arijsko-slovanske izoglose, ki jih navaja Porzig, Die Gliederung des idg. Sprachgebiets 168 : sti. kúha, gav. kuda kъde, "kje, ker«; sti. savyá-, av. haoya-, stesl. šujb »levi«; av.baya-, perz. baga-, stcsl. bogъ »bog«; oset. taxun itkati, stcsl. $t_{\mathrm{b}} k_{\ell}$ ntkem«.

\section{ZUSAMMENFASSUNG \\ EINE SLAWISCH - ALTINDISCHE ISOGLOSSE FŨR "ZEIT"}

In dem Manuskript seiner Besprechung des etymologischen Wörterbuches der serbokroatischen Sprache von P. Skok, die voraussichtlich in der Etimologija VII, Moskau, erscheinen wird, führt F. Bezlaj das sbkr. dial. č̀̀lo »Tag, zwölf Stunden«, dan $i$ noć su dva čela (Risanj, Bolka Kotorska) und in Montenegro kolje "Zeit, freie Zeit, Musse«, dòkolica «Musse« an und vermutet den slawischen Archaismus aus dem idg. *qwel- sörtlich und zeitlich fernu.

Mit diesen sbkr. Wörtern lässt sich das ai. kātá- "Zeit, Zeitpunkt, Tod, Schicksal" in Zusammenhang bringen, was Mayrhofer in seinem Kurzgefassten etymologischen Wörterbuch des Altindischen von dem idg. "quel- wsich drehen ableitet und dabei denselben Bedeutungsübergang für das aksl. vrěme "Zeit" zum idg. *wert- "sich wenden, sich drehen wsich drehenk aus, so musste die Bedeutung ähnlich wie noch im ai. kâlá- ursprünglich auch im sbkr. "(bestimmte) Zeitu sein.

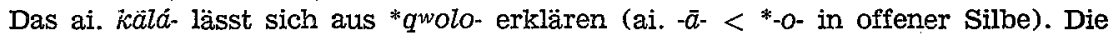
sbkr. Kolje und dokolica sind vermutlich mit bekannten Suffixen -je und -ica aus dem Stamm * qwolo- orweitert und demnach in der Grundlage mit dem ai. kālá- identisch, während bei dem sbkr. čèlo der ursprïngliche Stamm *gweles- vorliegen muss.

Die slawisch-altinđische Isoglosse sbkr. kolje, dòkolica, čèlo, ai. kälä- ist besonders interessant, weil gemeinsame Ausdrücke für den Begriff "Zeitu selten sind und so einzelne Sprachen dafuir grösstenteils besondere Ausdrücke entwickelt haben (vgl. aksl. c̆aş "Zeit», apreuss. kïsman "Zeit, Weile», alb. kohë "Zeit, Wetter" < idg. * $q \bar{e}$-sk'-; lat. tempus zum idg. *ten- usw.).

Die erwähnte Isoglosse können wir zu den seltenen arisch-slawischen Isoglossen zählen, die von Porzig, Die Gliederung des idg. Sprachgebiets 168, angeführt werden

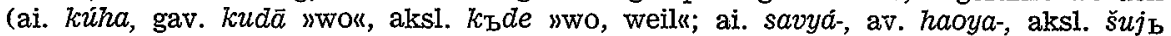
"links«; av. bay $a_{-}$, apers. baga-, aksl. bog "webew). 